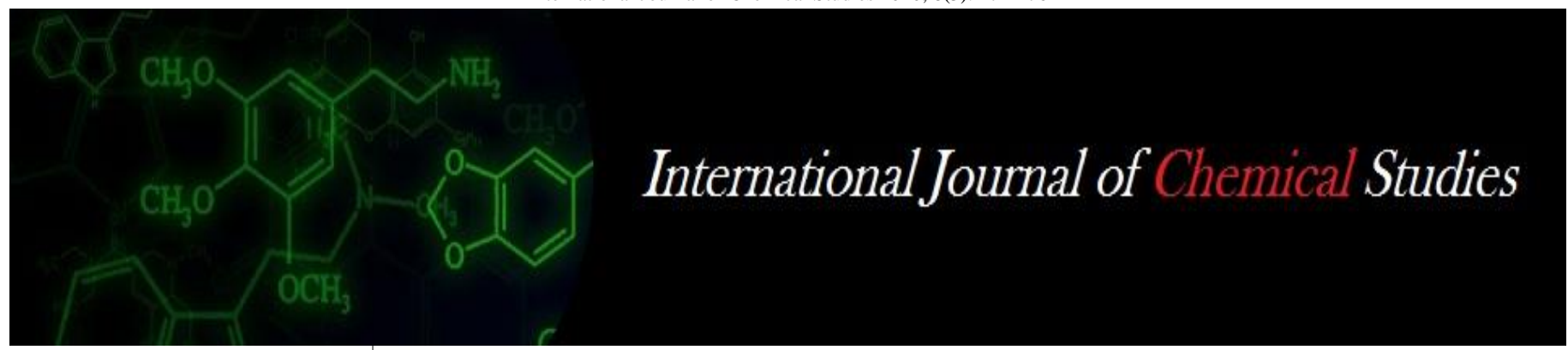

P-ISSN: 2349-8528

E-ISSN: 2321-4902

www.chemijournal.com

IJCS 2020; 8(3): 271-276

(C) 2020 IJCS

Received: 25-03-2020

Accepted: 27-04-2020

\section{Prafull Kumar}

Department of Agricultural

Biotechnology, College of

Agriculture, Sardar Vallabhai

Patel University of Agriculture

\& Technology, Meerut,

Uttar Pradesh, India

Vandana Sharma

Department of Agricultural

Biotechnology, College of

Agriculture, Sardar Vallabhai

Patel University of Agriculture

\& Technology, Meerut,

Uttar Pradesh, India

\section{RS Sanger}

Department of Agricultural

Biotechnology, College of

Agriculture, Sardar Vallabhai

Patel University of Agriculture

\& Technology, Meerut,

Uttar Pradesh, India

\section{P Kumar}

Department of Agricultural

Biotechnology, College of

Agriculture, Sardar Vallabhai

Patel University of Agriculture

\& Technology, Meerut,

Uttar Pradesh, India

\section{Manoj K Yadav}

Department of Agricultural

Biotechnology, College of

Agriculture, Sardar Vallabhai

Patel University of Agriculture

\& Technology, Meerut,

Uttar Pradesh, India
Corresponding Author:

Manoj K Yadav

Department of Agricultural

Biotechnology, College of

Agriculture, Sardar Vallabhai

Patel University of Agriculture

\& Technology, Meerut

Uttar Pradesh, India

\section{Analysis of molecular variation among diverse background wheat (Triticum aestivum $\mathrm{L}$ ) genotypes with the help of ISSR markers}

\author{
Prafull Kumar, Vandana Sharma, RS Sanger, P Kumar and Manoj K \\ Yadav
}

DOI: https://doi.org/10.22271/chemi.2020.v8.i3d.9240

\begin{abstract}
Inter Simple Sequence Repeat (ISSR) provide adequate information about polymorphism and reproducible fingerprinting profiles for evaluating heritable diversity in different crops including wheat. The main objective of this study was to reveal the genetic diversity and relationships among different wheat genotypes. Genomic DNA from twenty wheat genotypes were analyzed using 25 inter simple sequence repeats (ISSR) markers. Out of 25 ISSR primers, 16 showed high level of polymorphism and 9 primers were monomorphic in nature. 1.66 bands per primer were amplified on an average. The PIC value varied from 0.048 to 0.747 for 25 primers. RP value of 25 ISSR primers ranged from $0.95-1.96$ with an average of 1.57. The primer UBC 814 was reported as best one in distinguishing the 20 durum varieties. Similarity values for all the 20 genotypes ranges from 0.087 to 0.537 showing substantial differences among the wheat varieties. The 25 ISSR markers were used to construct the dendrogram based on UPGMA cluster analysis. The dendrogram indicates that the ISSR markers succeeded in distinguishing most of 20 varieties in relation to their genetic background and their geographical origin.
\end{abstract}

Keywords: Wheat, genetic variation, ISSR markers, molecular markers, polymorphism

\section{Introduction}

Wheat (Triticum aestivum L.) has wide adaptability and occupies an important position among the cereal crops in the world and in India also. It is grown in a much diversified environments (Belderok et al., 2000) ${ }^{[3]}$. Genetic diversity plays a significant role in plant molecular biology either to exploit heterosis or to generate productive recombinants or even more than this. The choice of parents is of vital importance in various breeding programmes. Therefore, the knowledge of genetic diversity and close relatedness in the germplasm is a pre-requisite for any crop improvement programmes. Reduction in the genetic variability makes the crops increasingly vulnerable to diseases and adverse climatic changes (Aboughadareh et al., 2017) [1]. Thus, precise information on the nature and degree of genetic diversity present among wheat collections from its principal areas of cultivation could help to select parents for evolving superior varieties (Singh et al., 2017) ${ }^{[19]}$. Inter simple sequence repeats (ISSRs) are one of the important DNA-based markers that have been widely used in the present era of plant research (Karaca et al., 2008) ${ }^{[12]}$. ISSR marker system is considered as one of the best choices to distinguish the genetic polymorphism in many higher plants including cereals (Zietkiewicz et al., 1994; Nagaoka and Ogihara, 1997) ${ }^{[23,15] .}$

Genetic diversity assessment at the molecular level is more meaningful in compare to phenotypic level as it involves data on morphological traits which are mainly depends on environmental factors (Brown et al., 2003) ${ }^{[4]}$. Therefore, they significantly contribute towards phenotypic variation. So the study of polymorphism is primarily done at the level of arrangement of nucleotide bases in DNA, which is the primary source of all the biological information (Akagi et al., 1996) ${ }^{[2]}$. We are well aware that molecular markers provide the best estimate of genetic diversity since they are independent of the confounding effects of environmental factors. Many research groups developed drought tolerant wheat cultivars with a wider and diverse genetic background to achieve improved wheat productivity (Qadir et al., 2017) ${ }^{[18]}$. Inter Simple Sequence Repeats (ISSR) markers have been the preferred molecular 
markers in crop biotechnology because of their properties of genetic co-dominance, high reproducibility and multi-allelic variation (Kantety et al., 1995) [11]. They are the most practical markers for genomic mapping, variety identification and marker-assisted selection. In cereals, ISSR markers have been widely used to study the genetic diversity, to know the phylogenetic relationships among the genotypes (Fernandez et al., 2002) ${ }^{[8]}$, for gene tagging in molecular assisted selection studies (Kaushik et al., 2003) ${ }^{[13]}$ and for DNA fingerprinting (Carvalho et al., 2005) ${ }^{[5]}$. In the present study we tried to reveal the genetic diversity among the wheat genotypes for drought traits using ISSR markers.

\section{Materials and Methods \\ Germplasm used}

A total of twenty diverse background wheat genotypes were used in this study including hexaploid, tetraploid and diploid varieties. The names and pedigree of these genotypes are given in Table 1. Germplasm was collected from Department of Genetic and Plant Breeding, SVPUA\&T Meerut and G. B. Pant University of Agriculture and Technology, Pantnagar, Uttarakhand.

\section{DNA isolation and ISSR analysis}

Genomic DNA was extracted from four weeks old young fresh leaves of 20 wheat genotypes grown in the departmental field laboratory, following the CTAB procedure described by Doyle and Doyle (1987) [7] with some modifications. The quantity and quality of genomic DNA was tested by the UV spectrophotometer and agarose gel electrophoresis. The genomic DNA and ISSR primers were used to produce bands of ISSR markers through PCR amplification. The sequence of 25 ISSR primers were custom synthesized by Merck Pvt. Ltd. PCR reactions were set using 25 primers as to analyse the 20 durum varieties to access genetic variation among the selected wheat genotypes.. PCR reaction was performed in $25 \mu \mathrm{l}$ volume containing: master mix beads, $3 \mu \mathrm{l}$ buffer (10 X), $2 \mu \mathrm{l}$ primer $(100 \mu \mathrm{lM}), 1 \mu \mathrm{l}$ DNA template $(25 \mathrm{ng}), 1 \mu \mathrm{l}$ Taq polymerase $(1 \mathrm{U} / \mu \mathrm{l}), 0.6 \mu \mathrm{dNTPs} \operatorname{mix}(100 \mathrm{mM})$ and $17.4 \mu \mathrm{l}$ water. The amplification was carried out in a thermocycler (Teckne ${ }^{\mathrm{TM}}$ ) programmed as follows: 1 cycle of $94{ }^{\circ} \mathrm{C} / 5 \mathrm{~min}$, 40 cycles of $\left(94{ }^{\circ} \mathrm{C} / 51 \mathrm{~min}, 51^{\circ} \mathrm{C} / 1 \mathrm{~min}\right.$ and $\left.72{ }^{\circ} \mathrm{C} / 2 \mathrm{~min}\right), 1$ cycle of $72{ }^{\circ} \mathrm{C} / 10 \mathrm{~min}$. The annealing temperatures of each ISSR primers were varied according to the melting point of each primer. For separating the PCR products of amplified DNA fragments agarose gel electrophoresis (2\%) was used to fractionate the amplicons.. Estimation of genetic similarity was done by Jaccard's coefficient. Resulting similarity matrix was further analysed using the unweighted pair-group method arithmetic average (UPGMA) clustering alogorithm; the computations were carried out using module of NTSYS-PC version 2.0 version.

Table 1: Wheat genotypes used in the present investigation for genetic diversity analysis.

\begin{tabular}{|c|c|c|}
\hline $\begin{array}{c}\text { S. } \\
\text { No. }\end{array}$ & Genotypes & Pedigree \\
\hline 1 & PBW 533 & PBW 343/PBW 138//PBW 343 \\
\hline 2 & UP 2425 & HD 2320/UP 2263 \\
\hline 3 & PBW 226 & C591/RN//JN/3/CHR/HD1941 \\
\hline 4 & DBW 16 & RAJ 3765/WR 484//HUW 468 \\
\hline 5 & DBW 17 & CMH79A.95/3*CNO 79//RAJ3777 \\
\hline 6 & DBW 71 & PRINIA/UP-2425/4361 \\
\hline 7 & PBW590 & WH 594/RAJ3814//W 485 \\
\hline 8 & K 607 & Not Available \\
\hline 9 & K 802 & Not Available \\
\hline 10 & K 9107 & Not Available \\
\hline 11 & K 1256 & HP1633/KAL/UP262 \\
\hline 12 & K 9423 & Not Available \\
\hline 13 & K 6525 & ATTILA \\
\hline 14 & HD 2733 & ATTILA /3/ TUI /CARC // CHEN / CHTO /4/ \\
\hline 15 & HD 2864 & CPAN 3004/WR 426//HW 2007 \\
\hline 16 & PBW 550 & WH-594/RAJ-3858//W-485; WH-594/RAJ- \\
\hline 17 & MP 4010 & H856//W-485 \\
\hline 18 & MP 3336 & HD2403/KAL/UP262 \\
\hline 19 & HD 3086 & DBW14/HD2733//HUW468 \\
\hline 20 & PBW 373 & ND/VG1944//KAL/BB/3/YACO'S'/4/VEE\#5'S' \\
\hline
\end{tabular}

Table 2: List of ISSR primers and their nucleotide (5'-3') sequence used in the genetic diversity analysis of wheat genotypes.

\begin{tabular}{|c|c|c|}
\hline S. NO. & Name & Primer Sequence \\
\hline 1. & UBC 811 & GAGAGAGAGAGAGAGAC \\
\hline 2. & UBC 812 & GAGAGAGAGAGAGAGAA \\
\hline 3. & UBC 813 & СТСТСТСТСТСТСТСТТ \\
\hline 4. & UBC 814 & СТСТСТСТСТСТСТСТА \\
\hline 5. & UBC 815 & СТCTCTCTCTCTCTCTG \\
\hline 6. & UBC 819 & GTGTGTGTGTGTGTGTA \\
\hline 7. & UBC 823 & TCTCTCTCTCTCTCTCC \\
\hline 8. & UBC 824 & TCTCTCTCTCTCTCTCG \\
\hline 9. & UBC 826 & ACACACACACACACACC \\
\hline 10 . & UBC 827 & ACACACACACACACACG \\
\hline 11. & WH1 & AGAGAGHGAGAGAGAGC \\
\hline 12. & WH2 & GTGTGTGTGTGTGTGTC \\
\hline 13. & WH3 & GACAGACAGACAGACA \\
\hline 14. & WH4 & СТСТСТСТСТСТСТСТG \\
\hline 15. & WH5 & CACACACACACACACAG \\
\hline 16. & WH6 & ACACACACACACACACC \\
\hline 17. & WHA & TATAAATCTTCTTAGTCAAC \\
\hline 18. & WHB & AGTGTGGTCCTACAGTG \\
\hline 19. & WHC & CACACACACACACACAG \\
\hline 20. & WHD & GAGAGAGAGAGAGAGAA \\
\hline 21. & WHE & СТСТСТСТСТСТСТСТА \\
\hline 22. & WHF & GATAGATAGACAGACA \\
\hline 23. & WHG & GCCTGAACCTGCTTTATC \\
\hline 24. & WHH & GAGAGCGGTCCATATTCC \\
\hline 25. & WHJ & TCGGAGAGTGATGGTTG \\
\hline
\end{tabular}




\section{Results and Discussion}

\section{Characterization of wheat varieties}

The performance characteristics of twenty different ISSR markers were evaluated in the present studies. Variation in the banding pattern of the amplification products occurs because of variation in the length of DNA sequences flanked by the primers. In this study twenty wheat genotypes were used for ISSR analysis. Some primers produced high degree of polymorphism but few primers did not produced polymorphism at all. Among 25 primers only 16 primers showed high level of polymorphism (100\%) and 9 primer were monomorphic in nature (Figure 1). On an average 1.66 bands per primer were amplified. The polymorphism information content (PIC) values derived from allelic diversity and frequency among the genotypes were not uniform for all the ISSR loci tested. The PIC value for 25 primers varied from 0.032 (UBC 826) to 0.747 (UBC 824). Lower PIC value may be the result of closely related genotypes and higher PIC values might be the result of diverse genotypes. It was observed that there is a substantial polymorphism recorded among the genotypes used for present investigation. Higher PIC can be explained that the primers used for molecular analysis are very much efficient to differentiate the closely related genotypes. Primer UBC 824 (0.747) showed higher PIC value whereas primer UBC 826 (0.032) showed lowest PIC value (Table 3). Resolving power is based on the distribution of the alleles with the sample genotypes. The most efficient means of separating any group for identification purposes to progressively divide the group into equal sub group. This provides the minimum path length for identification irrespective of the genetic makeup of the group being analysed (Prevost and Wilkinson, 1999) ${ }^{[17]}$. Resolving power of 25 ISSR primers varied in the range of 0.95 to 1.96 with an average of 1.57 . The highest resolving power was shown by primer UBC 814 (1.96) while primer
UBC 824 showed lowest resolving power (0.95) (Table 3). Accordingly, our results were in conformity with the previous studies (Prevost and Wilkinson, 1999; Yousefi et al., 2015) $[17,22]$ that resolving power can be proposed as the best indictors for selecting most useful primers. Thus, the significant value of resolving power indicated the ability of primers to resolve the different but closely related genotypes of wheat.

Average PIC value per primer was recorded as 0.357 , which was comparable to that reported by Zamanianfard et al., (2015) ${ }^{[24]}$ in evaluation of genetic diversity in durum wheat using ISSR markers, but was higher than PIC values obtained by Sofalian et al., (2009) [20] in evaluation of genetic difference of wheat genotypes using ISSR markers similar result recorded (Sharma et al. 2014 and Kumar et al., 2017) $[21,14]$ in the range 0.38 to 0.83 on an average 0.53 and 0.05 to 0.46 with an average of 0.23 , respectively. It was observed that marker detecting the lower number of alleles showed lower gene diversity than those detected higher number of alleles which revealed higher gene diversity. These results are consistent with previous work done by other co-workers who also observed that the genetic diversity at each ISSR locus was significantly correlated with the number of alleles detected, type and range of repeat motif of microsatellite markers and with the allele size range.

ISSR marker technique, which is relatively cheaper and requires small quantities of DNA, it was possible to identify one primer from ISSR that generated polymorphic bands in diverse background of wheat varieties. These bands can be considered as potential markers to identify different traits related to abiotic and abiotic stress or may be more useful when converted into simple-sequence PCR-based markers that can be used for large scale screening of cultivars (John et al., 2012) ${ }^{[10]}$. Hence, there is a need of more and more ISSR markers in wheat germplasm to reveal the genetic diversity.

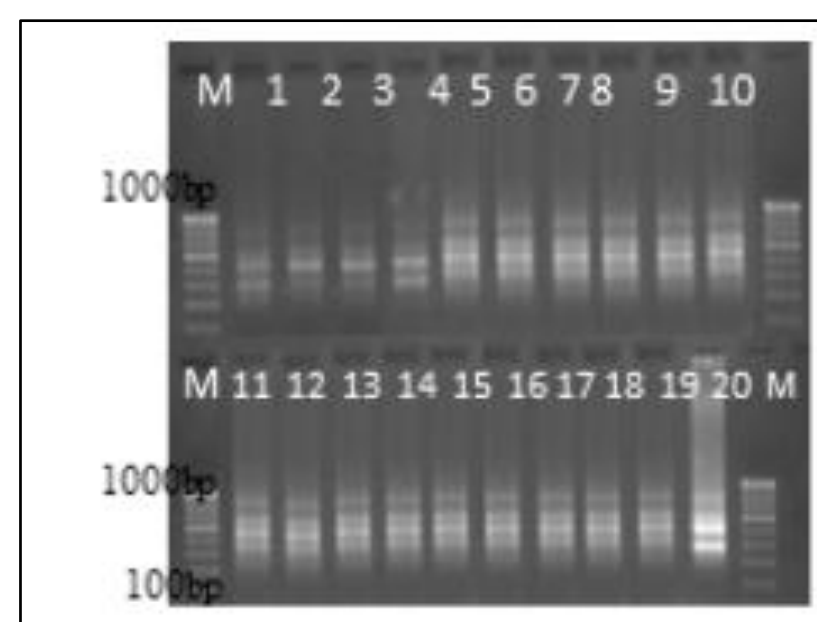

(a) UBC 815

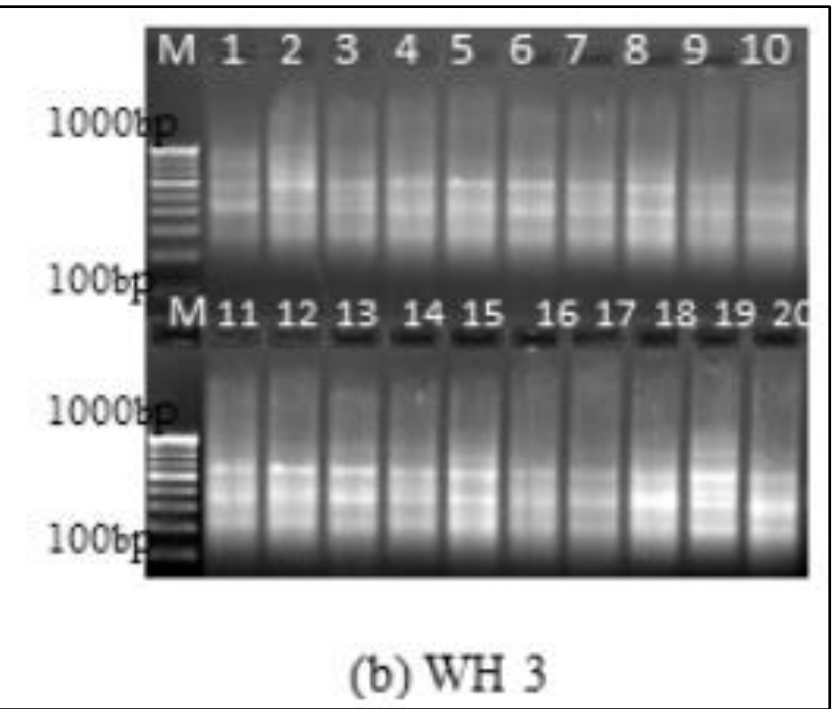



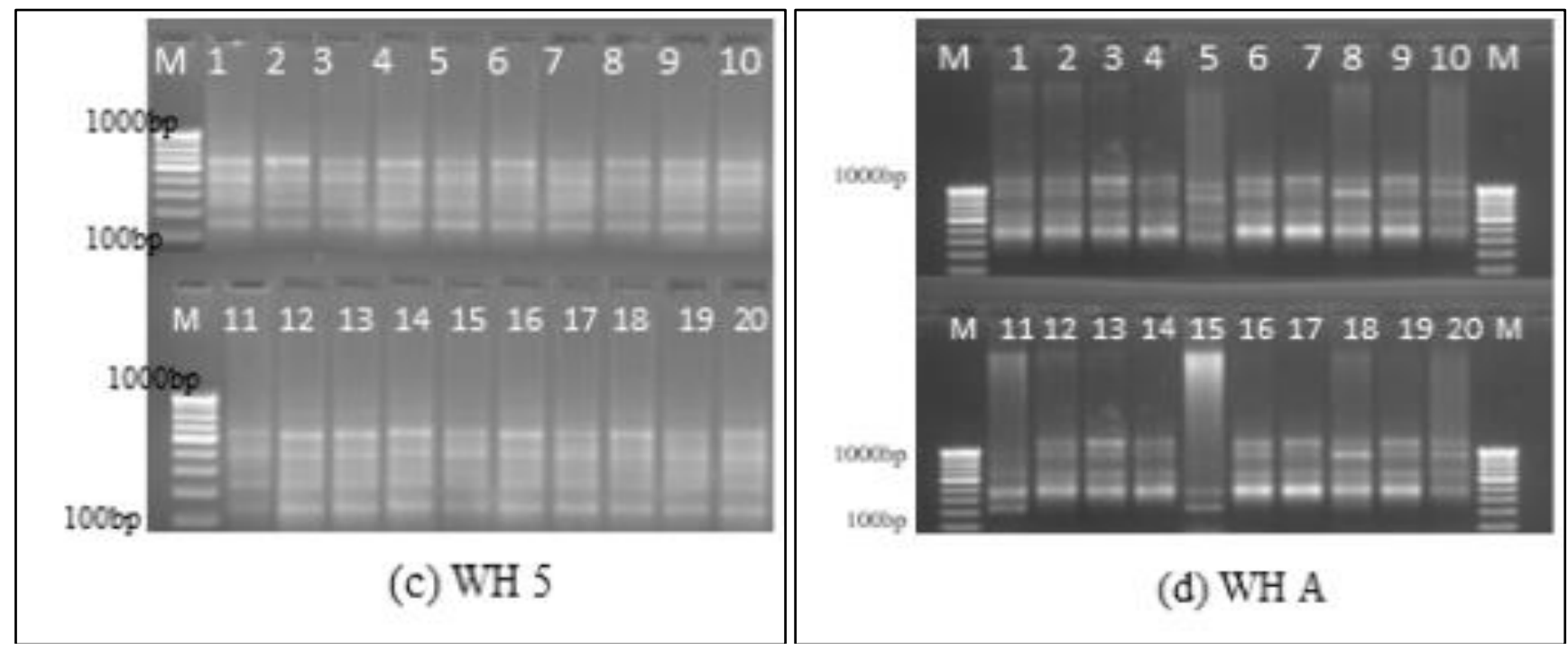

Fig 1: ISSR banding patterns of twenty wheat genotypes showing variation among wheat genotpyes.

Table 3: Number of total bands, monomorphic and polymorphic bands and percentage of polymorphism obtained per each ISSR primers for wheat genotypes used in the present study.

\begin{tabular}{|c|c|c|c|c|c|c|c|}
\hline $\begin{array}{c}\text { S. } \\
\text { No }\end{array}$ & Primers & $\begin{array}{c}\text { Total } \\
\text { Band }\end{array}$ & MB & PB & $\begin{array}{c}\text { PIC } \\
\text { value }\end{array}$ & RP & $\begin{array}{c}\text { Polymorphism } \\
\text { \% }\end{array}$ \\
\hline 1 & UBC 811 & 4 & 0 & 4 & 0.504 & 1.34 & $100 \%$ \\
\hline 2 & UBC 812 & 4 & 0 & 4 & 0.377 & 1.324 & $100 \%$ \\
\hline 3 & UBC 813 & 3 & 0 & 3 & 0.449 & 1.7 & $100 \%$ \\
\hline 4 & UBC 814 & 4 & 0 & 4 & 0.392 & 1.966 & $100 \%$ \\
\hline 5 & UBC 815 & 2 & 0 & 2 & 0.134 & 1.85 & $100 \%$ \\
\hline 6 & UBC 819 & 3 & 0 & 3 & 0.456 & 1.466 & $100 \%$ \\
\hline 7 & UBC 823 & 3 & 1 & 2 & 0.234 & 1.732 & $66.66 \%$ \\
\hline 8 & UBC 824 & 4 & 0 & 4 & 0.747 & 0.95 & $100 \%$ \\
\hline 9 & UBC 826 & 3 & 2 & 1 & 0.32 & 1.466 & $33.33 \%$ \\
\hline 10 & UBC 827 & 3 & 0 & 3 & 0.450 & 1.432 & $100 \%$ \\
\hline 11 & WH1 & 4 & 0 & 4 & 0.357 & 1.6 & $100 \%$ \\
\hline 12 & WH2 & 5 & 1 & 4 & 0.458 & 1.42 & $80 \%$ \\
\hline 13 & WH3 & 4 & 3 & 1 & 0.245 & 1.57 & $25 \%$ \\
\hline 14 & WH4 & 4 & 0 & 4 & 0.332 & 1.7 & $100 \%$ \\
\hline 15 & WH5 & 4 & 2 & 2 & 0.048 & 1.95 & $50 \%$ \\
\hline 16 & WH6 & 3 & 0 & 3 & 0.436 & 1.432 & $100 \%$ \\
\hline 17 & WHA & 5 & 1 & 4 & 0.332 & 1.48 & $80 \%$ \\
\hline 18 & WHB & 5 & 0 & 5 & 0.366 & 1.56 & $100 \%$ \\
\hline 19 & WHC & 3 & 0 & 3 & 0.576 & 1.3 & $100 \%$ \\
\hline 20 & WHD & 3 & 0 & 3 & 0.356 & 1.6 & $100 \%$ \\
\hline 21 & WHE & 5 & 1 & 4 & 0.142 & 1.55 & $80 \%$ \\
\hline 22 & WHF & 2 & 0 & 2 & 0.536 & 1.65 & $100 \%$ \\
\hline 23 & WHG & 3 & 0 & 3 & 0.452 & 1.466 & $100 \%$ \\
\hline 24 & WHH & 2 & 1 & 1 & 0.180 & 1.8 & $50 \%$ \\
\hline 25 & WHJ & 4 & 2 & 2 & 0.049 & 1.95 & $50 \%$ \\
\hline & Total & 89 & 14 & 75 & 8.928 & 39.254 & \\
\hline & Average & 1.97 & 3.11 & 1.66 & 0.357 & 1.57 & \\
\hline & & & & & & \\
\hline
\end{tabular}

\section{Genetic Similarity and cluster analysis of different wheat} genotypes

The relationships among different wheat genotypes were estimated by a UPGMA cluster analysis of genetic similarity matrices. The genetic similarity index and dendogram tree of the 20 durum genotypes under the present study was performed using Jaccard's similarity on the basis of ISSR amplified fragments as shown in Fig. 2. In the phylogenetic analysis, most of the wheat genotypes were clustered together in respect to their molecular characterization and thus, might have a similar genetic background. Those clustered within the same group or subgroups are mostly from the same origin and those which are distantly grouped were from different geographical locations. Similarity index value for all the twenty genotypes ranged from 0.087 to 0.537 and two most closely related and diverse genotype in the twenty wheat genotypes have been observed in the present investigation (Table 4). The highest similarity was observed among four genotypes, HD 2733, PBW 533, PBW 590 and UP 2425. The minimum genetic similarity was observed by two genotypes, DBW 71 and DBW 16. Range of similarity index among all genotypes was from 0.08 to 0.54 . Similar results were also observed by Hemaprabha et al. (2013) ${ }^{[9]}$ and Choudhary et al. (2017) ${ }^{[6]}$; which were in the range of 0.43 to 0.86 in wheat. Cluster analysis of twenty wheat genotypes revealed that all the used genotypes grouped into two major clusters namely A and B. Cluster A consist of two sub clusters A1 and A2 of which cluster A1 is further sub divided into two sub sub clusters $\mathrm{C}$ and $\mathrm{D}$. Cluster $\mathrm{B}$ of the main cluster consists of two sub clusters B1 and B2. Group B1 is sub divided into three sub clusters Viz. I1, I2 and I3. Sub cluster B2 is divided two sub sub clusters $\mathrm{K}$ and $\mathbf{J}$ (Fig. 2).

Our study revealed that genotypes falls in cluster A2 PBW 533 is distantly related to other genotypes. The composition of clusters obtained using ISSR markers revealed similar groupings in many cases with few variations but some genotypes showed higher range of genetic divergence due to wide range of genetic bases. These results are consistent with previous work done by other co-workers who also observed that the genetic diversity at each ISSR locus was significantly correlated with the number of alleles detected, type and range of repeat motif of microsatellite markers and with the allele size range. The higher genetic distance between them indicates that genetically they are diverse compare to lower genetic distance value. Basically these values are an indication of their genetic dissimilarity. Genotypes pair with higher value is more dissimilar than a pair with a lower value.

\section{Acknowledgement}

Authors are thankful to Director Research SVPUA\&T Meerut for providing all the necessary facilties for conduction of the experiments successfully. 


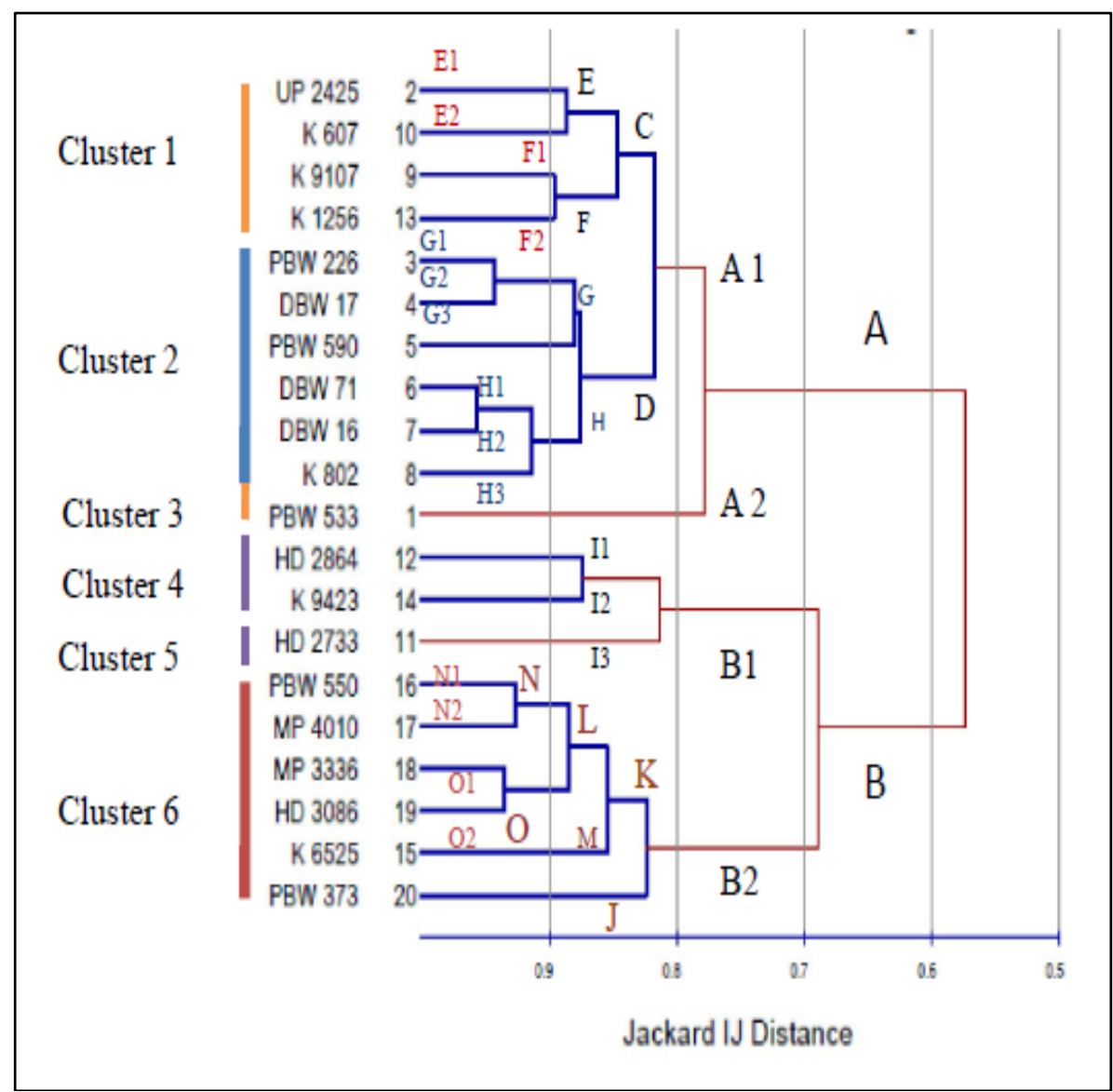

Fig 2: Dendogram representing the genetic relationship among the 20 durum varieties using UPGMA cluster analysis of Jaccard's similarity coefficient generated from ISSR markers.

Table 4: Similarity matrix of jaccard coefficient across the twenty wheat genotypes

\begin{tabular}{|c|c|c|c|c|c|c|c|c|c|c|c|c|c|c|c|c|c|c|c|c|c|}
\hline & $\begin{array}{c}\text { PBW } \\
\mathbf{5 3 3}\end{array}$ & $\mid \begin{array}{c}\text { UP } \\
2425\end{array}$ & $\begin{array}{c}\text { PBW } \\
226\end{array}$ & $\begin{array}{c}\text { DBW } \\
17\end{array}$ & $\begin{array}{c}\text { PBW } \\
590\end{array}$ & $\begin{array}{c}\text { DBW } \\
71\end{array}$ & $\begin{array}{c}\text { DBW } \\
16\end{array}$ & \begin{tabular}{|c|}
$\mathbf{K}$ \\
$\mathbf{8 0 2}$ \\
\end{tabular} & $\begin{array}{c}\mathbf{K} \\
\mathbf{9 1 0 7} \\
\end{array}$ & \begin{tabular}{c|}
$\mathbf{K}$ \\
$\mathbf{6 0 7}$ \\
\end{tabular} & $\begin{array}{c}\text { HD } \\
2733 \\
\end{array}$ & $\begin{array}{c}\text { HD } \\
2864\end{array}$ & \begin{tabular}{|c|}
$K$ \\
1256 \\
\end{tabular} & \begin{tabular}{|c|} 
\\
9423 \\
\end{tabular} & \begin{tabular}{|c|}
$K$ \\
6525 \\
\end{tabular} & $\begin{array}{c}\text { PBW } \\
550 \\
\end{array}$ & $\begin{array}{c}\text { MP } \\
\mathbf{4 0 1 0}\end{array}$ & $\begin{array}{c}\text { MP } \\
\mathbf{3 3 3 6}\end{array}$ & $\begin{array}{c}\text { HD } \\
3086 \\
\end{array}$ & $\begin{array}{c}\text { PBW } \\
\mathbf{3 7 3} \\
\end{array}$ & $\begin{array}{c}\text { Averag } \\
D^{2} \\
\end{array}$ \\
\hline PBW 533 & & \begin{tabular}{|l|}
0.3 \\
\end{tabular} & 0.35 & \begin{tabular}{|l|}
0.32 \\
\end{tabular} & 0.28 & 0.35 & \begin{tabular}{|l|}
0.39 \\
\end{tabular} & 0.35 & 0.36 & \begin{tabular}{|l|}
0.39 \\
\end{tabular} & 0.54 & 0.42 & 0.34 & 0.44 & 0.39 & 0.35 & 0.4 & 0.31 & 0.33 & 0.41 & 0.37 \\
\hline UP 2425 & 3 & & & & & & 0.24 & 0.19 & 0.24 & 0.23 & .46 & & 28 & 0.39 & 0.43 & & & & & & \\
\hline PBW 226 & 35 & 0.23 & & & & 1 & 13 & 0.19 & 0.24 & 0.3 & .38 & & 22 & 0.35 & 0.35 & & & & & & \\
\hline DBW 17 & 32 & 0.2 & 12 & & $\mathrm{c}$ & 2 & & 0.18 & 23 & 0.27 & 4 & & 26 & .32 & 0.36 & & & & & & \\
\hline PBW & & 24 & & & & & & 0.22 & 28 & 0.24 & 4 & & 23 & 32 & 35 & & & & & & \\
\hline$\overline{\mathrm{DBI}}$ & & 0.27 & & & & & & 0.17 & 0.24 & 0.28 & 0 & & 0.27 & .35 & .33 & & & & & & \\
\hline$\overline{\mathrm{DBI}}$ & & 0.24 & & & & & & \begin{tabular}{|l|}
0.13 \\
\end{tabular} & 0.23 & 0.22 & 0 & & 21 & 31 & .33 & & & & & & \\
\hline & & 19 & & & & & 13 & & 0.22 & 0.23 & 0 & & .24 & 33 & .33 & & & & & & \\
\hline & & 0.24 & ( & & & & 23 & 0.22 & & 0.24 & 2 & & 21 & .32 & 0.38 & & & & & & \\
\hline K 6 & & 23 & & & & & & 0.23 & 0.24 & & .3 & & 0.29 & 0.33 & 0.39 & & & & & & \\
\hline & & .46 & & & & & & 0.44 & 0.41 & 0.38 & & & 0.38 & 0.42 & 0.4 & & 2 & & & & \\
\hline & & 0.35 & 5 & & & & 25 & 0.27 & 0.28 & 0.31 & 0.26 & & 0.21 & 0.25 & 0.32 & 0.2 & 0.3 & & & & \\
\hline & 0 & 0.28 & 22 & & & & 21 & 0.24 & 0.21 & 0.29 & 0.38 & & & 0.28 & 0.3 & 0. & & 22 & & & \\
\hline & & 0.39 & & & & & & 0.33 & 0.32 & 0.33 & 0.4 & & 0.28 & & 0.3 & 0. & & & & & \\
\hline & & 0.43 & & & & & & 0.33 & 0.38 & 0.39 & 0.4 & & 0.3 & 0.3 & & 0. & & & & & \\
\hline & 35 & 0.35 & & & & & & 0.27 & 0.28 & 0.31 & 0.4 & & 0.3 & 0.28 & 0.2 & & 0.15 & 0.19 & & & \\
\hline & & 0.36 & & & & & & 0.29 & 0.36 & 0.33 & & & 0.3 & 0.3 & 0.26 & & & & & & \\
\hline & 31 & 0.31 & 0.28 & & & & & 0.21 & 0.24 & 0.3 & 0.42 & & 0.22 & 0.35 & 0.27 & & & & & & \\
\hline & 33 & 0.34 & 0.32 & & & & & 0.28 & $\begin{array}{l}0.29 \\
\end{array}$ & 0.3 & 0.5 & & 0.27 & 0.35 & 0.25 & & 0.21 & & & 0.25 & \\
\hline BDW $3 / 3$ & \begin{tabular}{|l|}
0.41 \\
\end{tabular} & 0.33 & 0.33 & & 0.3 & 0.31 & 0.31 & 0.29 & 0.34 & 0.35 & 0.49 & 0.32 & 0.32 & 0.35 & \begin{tabular}{|l|}
0.37 \\
\end{tabular} & 0.26 & 0.3 & 0.27 & 0.25 & & 0.33 \\
\hline
\end{tabular}

\section{Conclusion}

This study demonstrated the potential efficiency of ISSR markers to detect genetic diversity in different wheat varieties. The PIC values derived from allelic diversity and frequency among the genotypes were not uniform for all the ISSR loci tested. The PIC value for 25 primers varied from 0.048 (WH 5) to 0.747 (UBC 824) with an average mean of 0.357. Lower PIC value may be the result of closely related genotypes and higher PIC values might be the result of diverse genotypes. ISSR markers of the present study revealed substantially higher level polymorphism among twenty wheat genotypes studied in the present investigation.

\section{References}

1. Aboughadareh AP, Ali JA, Mehrabi A, Etminan A, Mohammad MM. Insight into the genetic variability analysis and relationships among some Aegilops and Triticum species, as genome progenitors of bread wheat, using SCOT markers. Plant Biosystem. 2017; 3(1):1-9.

2. Akagi H, Yokozeki Y, Inagaki A, Nakamura A, Fujimura T. A codominant DNA marker closely linked to the rice 
nuclear restorer gene, Rf-1, identified with inter-SSR fingerprinting. Genome. 1996; 39(6):1205-1209.

3. Belderok B, Mesdag J, Donner DA. Assay methods and instrumentation. In D. A. Donner (Ed.), Bread-making quality of wheat: a century of breeding in Europe. Dordrecht, Netherland: Springer Science and Business Media, 2000, 67-86.

4. Brown AHD, Weir BS. Measuring genetic variability in plant populations, 219-239 in Isozymes in Plant Genetics and Breeding, part A (S.D. Tanksley and T.J. Orton, eds.). Elsevier Science Publishers, Amsterdam, 1983.

5. Carvalho A, Matos M, Lima-Brito J, Guedes-Pinto H, Benito C. DNA fingerprint of F1 interspecific hybrids from the Triticeae tribe using ISSRs. Euphytica. 2005; 143:93-99.

6. Chaudhari, Sunbal Khalil, Arshad Muhammad, Ilyas Noshin. Physiological and biochemical responses of hexaploid wheat cultivars to drought stress. Pure Appl. Biol. 2017; 6(1):60-71.

7. Doyle JJ, Doyle JL. A rapid DNA isolation procedure for small quantities of fresh leaf tissue. Phytochemical Bulletin. 1987; 19:11-15.

8. Fernández ME, Figueiras AM, Benito C. The use of ISSR and RAPD markers for detecting DNA polymorphism, genotype identification and genetic diversity among barley cultivars with known origin. Theor Appl Genet. 2002; 104:845-851.

9. Hemaprabha $\mathrm{K}$, Hemalatha $\mathrm{T}$, Uma Maheswari $\mathrm{T}$, Anbukkarasi K, Shanmugasundaram P. Genetic diversity analysis of anther culture derived rice plants using molecular markers. International J Advanced Res. 2013; 1(5):103-112.

10. John Z, Yu, Russell J, Kohel DD et al. A High-Density Simple Sequence Repeat and Single Nucleotide Polymorphism Genetic Map of the Tetraploid Cotton Genome. Genes, Genomes, Genetics. 2012; 2(1):43-58.

11. Kantey RV, Zeng XP, Bennetzen JL, Zehr BE. Assessment of genetic diversity in dent and popcorn (Zea mays L.) inbred lines using Inter-simple sequence repeat (ISSR) amplification. Mol. Breed. 1995; 1:365-373.

12. Karaca M, Izbirak A. Comparative analysis of genetic diversity in Turkish durum wheat cultivars using RAPD and ISSR markers. J Food Agric. Environ. 2008; 6:219225.

13. Kaushik A, Saini N, Jain S et al. Genetic analysis of a CSR10 (indica) $\times$ Taraori Basmati F3population segregating for salt tolerance using ISSR markers. Euphytica. 2003; 134:231.

14. Kumar S, Dwivedi SK, Kumar R et al. Productivity and energy use efficiency of wheat (Triticum aestivum) genotypes under different tillage options in rainfed ecosystem of middle Indo-Gangetic Plains. Indian $\mathbf{J}$ Agronomy. 2017; 62(1):31-38.

15. Nagaoka T, Ogihara Y. Applicability of inter-simple sequence repeat polymorphisms in wheat for use as DNA markers in comparison to RFLP and RAPD markers. Theor Appl Genet. 1997; 94(5):597-602.

16. Najaphy A, Parchin RA, Farshadfar E. Comparison of phenotypic and molecular characterizations of some important wheat cultivars and advanced breeding line. Australian J Crop Sci. 2012; 6(2):326-331.

17. Prevost A, Wilkinson MJ. A new system of comparing PCR primers applied to ISSR fingerprinting of potato cultivars. Theor Appl Genet. 1999; 98:107-112.
18. Qadir SA, Mohammed Q, Khursheed MQ, Huyop FZ. Drought Tolerance and Genetic Diversity among Selected Wheat Cultivars. ZANCO J Pure and Applied Sciences. 2017; 29(3):110-117.

19. Singh T, Singh V, Singh KP et al. $\mathrm{D}^{2}$ analysis in certain promising genotypes of wheat (Triticum aestivum L. em. Thell) J Pharmaco and Phytochem. 2017; 6(5):27142717.

20. Sofalian ON, Chaparzadeh, Dolati M. Genetic diversity in spring wheat landraces from northwest of Iran assessed by ISSR markers. Notul. Bot. Hort. Agric., Cluj-Napoca. 2009; 37:252-256.

21. Sharma P, Sareen S, Saini M, Verma A et al. Assessing genetic variation for heat tolerance in synthetic wheat lines using phenotypic data and molecular markers. Aust J Crop Sci. 2014; 8:515-522.

22. Yousefi V, Najaphy A, Zebarjadi A, Safari S. Molecular characterization of thymus using ISSR markers. Journal Animal and Plant Sci. 2015, 25(4):1087-1094.

23. Zietkiewicz E, Rafalski A, Labuda D. Genome fingerprinting by simple sequence repeat (SSR)-anchored polymerase chain reaction amplification. Genomics. 1994, 20:176-183.

24. Zamanianfard, Zahra, Etminan Alireza, Mohammadi Reza, Shooshtari Lia. Evaluation of Molecular Diversity of durum wheat genotypes using ISSR markers. Biological Forum - An International Journal. 2015; 7(1):214-218. 